\section{INTERSEX STATES*}

BY

\section{G. L. FOSS, O.B.E., V.R.D., M.A., M.D. \\ Clinical Assistant to Endocrine Clinics, United Bristol Hospitals}

It is obviously very important, psychologically, to make a firm and accurate diagnosis of the correct sex well before puberty. In the future some of these conditions and their problems may be rarities. In this paper the various types of sexual aberration which may be seen by the gynaecologist at the present time are discussed.

At this stage it is best to establish the criteria of sex, as so many factors are involved. Firstly, there is the physical status, observed by examination of both external and internal genitalia and the gonads, the absence or nature of the secondary sexual characteristics, and the menstrual history. Then both the sex psyche and the social sex of the patient are of great importance, and, in addition, we now have the opportunity of determining the presence or absence of sex chromatin in somatic nuclei, and in some centres of actually recording the chromosomal pattern. It is only after careful consideration of all these factors that an ultimate decision can be made. Generally speaking, treatment, if required, must be chiefly influenced by the social and psychological sex of the patient. However, it is probably unethical to consider these latter factors alone, without the support of at least some complementary physical or genetic evidence.

The various genetic aberrations have already been described, and it is suggested that two $\mathrm{X}$ chromosomes are necessary for the development of the normal female gonadal cortex, and that a $\mathbf{Y}$ chromosome is essential for development of the male gonadal medulla (Stewart, 1959a). This normally occurs in the embryo during the fourth to sixth week, and before this time the gonadal anlage is an indifferent organ.

Jost (1953) showed that rabbits, whether genetically male or female, developed female internal and external genitalia if the gonads were removed during early cmbryonic development. Thus in the absence of gonads a female phenotype develops regardless of the chromosomal sex of the individual. Even when the sex has been genetically determined as male with $\mathrm{XY}$ chromosomes, other factors, genetic or non-genetic, may be necessary to ensure sexual differentiation into the male phenotype, and eunuchoid females have been reported with XY chromosomes (Harnden and Stewart, 1959).

In addition to the sex chromosomal changes and other genetic possibilities, the development of the external genitalia of the female embryo of 11-20 weeks is influenced by abnormal androgens, whether these are of endogenous adrenal origin due to a metabolic error (Jailer. 1953) and apparently due to an autosomal recessive factor (Stewart, 1959b), or whether they are given to the mother in the form of androgens or progestogens in early pregnancy. In such cases the ovaries are merely suppressed, but the external genitalia are remarkably virilized and sometimes ambiguous.

* Read to the Section of Obstetrics and Gynaecology at the Annual Meeting of the British Medical Association, Torquay, 1960.
Sexual anomalies can be classified as follows: Congenital Conditions

1. Aberrations due to chromosomal defects:

(a) True hermaphrodite, XX/XY or mosaics.

(b) Gonadal dysgenesis with a male phenotype Klinefelter XXY.

(c) Turner's syndrome, $\mathrm{XO}$ or XX.

(d) Gonadal dysgenesis, $\mathrm{XO}, \mathrm{XX}$, or $\mathrm{XY}$ with a female phenotype.

(e) Superfemale or metafemale, XXX.

2. Other genetic defects:

(a) Testicular feminization or male pseudohermaphrodite, XY.

(b) Male with undescended testicles, hypospadias, and female micturition brought up as a female. XY.

3. Embryonic virilization:

(a) Pseudohermaphrodite, XX.

(b) Steroid-induced pseudohermaphrodite, XX

(c) Adrenal virilism after differentiation of external genitalia, XX.

Post-natal Conditions

(a) Adrenogenital syndrome- $\bigcup_{\text {tumour }}^{\text {adenoma }} \mathrm{XX}$

(b) Stein-Leventhal syndrome, XX.

(c) Constitutional virilism, XX.

(d) Male-type tumour, XX: arrhenoblastoma ; hilarcell tumour; adrenal rest tumour.

Steroid-induced pseudosex

(a) Pseudofemale, XY.

(b) Pseudomale, XX

\section{True Hermaphrodites}

These are rare, only about 60 cases having been described, and in about $70 \%$ the social sex was male. Diagnosis can be made only by gonadal biopsy. Hinman (1935) describes three types: (1) bilateral, with an ovary and a testis on both sides, or bilateral ovotestes ; (2) unilateral, with testis and ovary separate or united on one side and an ovary or testis on the other : and (3) lateral, or alternating, with a testis on one side and an ovary on the other.

It is not surprising that the variations of the clinical state are many.

Arneaud, Annamunthodo, Pinkerton, and Cole (1956) described the case of an apparent feminized male of 18 years whose nuclear sex was shown to be female; he was shown to have one ovary and an ovotestis. Barr (1955) determined the nuclear sex of nine such patients and found six with female-type nuclei and three with absent sex chromatin.

Harnden and Armstrong (1959) investigated a masculine female of 70 years with one ovotestis and found 46 chromosomes with XX sex chromatin pattern, and most tissue nuclei were chromatin-positive. However, Stewart (1959b) stated that true hermaphrodites might be mosaics of XX and XY or XXY gonadal tissue. but their status is still not clear.

\section{Gonadal Dysgenesis}

In males there is every gradation from complete agenesis of Leydig cells and tubules with eunuchoidism to the apparently normal virilized male with some degree of tubular dysgenesis, and azoospermia or oligozoospermia. The syndrome described by Klinefelter, Reifenstein, and Albright (1942) consists of gynaecomastia, small testes, absence of spermatogenesis, 
and an increased urinary excretion of follicle-stimulating hormone. - Heller and Nelson $(1945,1948)$ subdivided the condition into three main types. At one end of the scale there were eunuchoid features-that is, dysgenesis of Leydig cells and tubules; these showed little gynaecomastia, whereas if the Leydig cells were relatively unaffected there was gross gynaecomastia. All these testes show small tubules with absent spermatogenesis, but hyalinization of the basement membranes is not an invariable finding. A large majority of these cases are chromatin-positive $\mathrm{XXY}$, but some are chromatinnegative XY (Grumbach, Blanc, and Engle, 1957 ; Stewart, Ferguson-Smith, Lennox, and Mack, 1958). They are all sterile, and the chromatin-positive cases made up $3 \%$ of all patients attending a male infertility clinic (Ferguson-Smith, Lennox, Mack, and Stewart, 1957). So, too, in the female, ovarian dysgenesis can be associated with varying degrees of ovarian defect. Turner's syndrome is perhaps the best-known form and usually shows complete ovarian agenesis, sex-linked with other genetic defects, such as dwarfism, web-neck, cubitus valgus, abnormal facial or cranial development, and anomalies of the cardiovascular or urogenital systems. These usually have a chromosome pattern XO, but some may be XX.

However, pure gonadal dysgenesis may be seen without dwarfism and other sex-linked defects. The clinical features will naturally depend on the degree of ovarian deficiency. Thus one may see a tall eunuchoid female with absent secondary sexual characteristics and a hypoplastic uterus, or a girl with immaturely developed breasts and nipples, with primary amenorrhoea or a short-lived menstrual history, followed by amenorrhoea or oligomenorrhoea or possibly only infertility due to failure of ovulation.

Sex chromatin may be absent in the nuclei of some cases or present in a smaller proportion than in the normal female.

In a case recently described by Harnden and Stewart (1959) a tall eunuchoid girl of 19 with primary amenorrhoea, absent breasts, and scanty pubic and axillary hair was found to have normal external genitalia and uterus, but no gonads were palpated. Oestrogen withdrawal bleeding was induced, but she had no sex chromatin and her chromosome pattern was XY. They state that in the absence of gonads a female phenotype develops regardless of the chromosomal sex of the individual and that the possession of a $\mathrm{Y}$ chromosome is not sufficient to ensure the development of a male phenotype.

\section{The Superfemale}

Only one case has so far been reported (Jacobs, Baikie, Court Brown, MacGregor, Maclean, and Harnden, 1959b). Their patient was a woman of 35 who presented with secondary amenorrhoea. Menstruation started at 14 and occurred irregularly every two to three months until 19. Her breasts, vulva, vagina, uterus, and cervix were all small. Ovarian biopsy showed a normal stroma but only two follicles and no corpora albicantia.

Buccal smears showed a greater proportion $(71 \%)$ of nuclear chromatin bodies than in the normal woman $(36-51 \%)$ and some of the nuclei contained two chromatin bodies. Chromosome analysis revealed a count of 47 chromosomes with an XXX constitution. The term "metafemale" is preferred for this condition by Stern (1959).

\section{Testicular Feminization, or Male Pseudohermaphrodite}

These patients may have well-developed breasts, scanty pubic and axillary hair, and normal external genitalia, but there is usually an absent or very short vagina and an absent or vestigial uterus. They may present because of primary amenorrhoea or with herniae or labial swelling. There is an absence of sex chromatin in the buccal smears, and at operation the gonads are quite obvious testes, which either are histologically normal with some degree of spermatogenesis or they may show the cryptorchid pattern.

These gonads produce female hormone and if they are removed the breasts atrophy and menopausal symptoms ensue (Goldberg and Maxwell, 1948).

In four such cases a chromosomal sex of XY pattern was demonstrated by Jacobs, Baikie, Court Brown, Forrest, Roy, Stewart, and Lennox (1959a) who describe them as sex-reversed males. The male with undescended testicles and hypospadias who has been brought up as a girl also has XY chromosome pattern and other signs of virilization. It is probable that these will usually be recognized before adult life.

\section{Pseudohermaphroditism}

In these cases there is a large phallus with a persistent urogenital sinus. Precocious puberty with virilization occurs, with the result that growth is rapid at first, but ceases prematurely with early closure of the epiphyses. The voice is deep, the body hirsute, and there is no breast development, and primary amenorrhoea is the rule. The ovaries and uterus are small but normal in position. There is often a family history of endocrine disease, and siblings may be affected (Broster, Patterson, and Camber, 1953). In all the cases I have seen the social and psychological sex and the nuclear sex have been female. If the adrenal disturbance occurs after the fourth month of foetal life, when the external genitalia have developed, the child is born with hypertrophy of the clitoris but without a urogenital sinus (Wilkins, 1957). The excretion of 17 -ketosteroids is always high, and it rapidly falls on the administration of prednisolone or dexamethasone, given to suppress the adrenal cortex. If this treatment is given early and continuously before puberty the patient will develop into a normal female with regular menstruation, and several have given birth to normal children.

\section{Therapeutic or Steroid-induced Pseudohermaphrodite}

Women who have received androgen or progestogen therapy for repeated miscarriages or haemorrhage during early pregnancy may give birth to female babies with congenital defects of the external genitalia similar to those of the pseudohermaphrodite (Wilkins, Jones, Holman, and Stempfel, 1958 ; Hayles and Nolan, 1958 ; Nellhaus, 1958 ; Moncrieff, 1958).

\section{Post-natal Conditions}

All this group show some degree of virilization and a normal XX chromosomal pattern. In the adrenogenital syndrome virilism occurs, and at any age after birth. The clinical picture will obviously depend on the time of onset before or after puberty and the nature of the source and rate of production of androgens-that is, hyperplasia and simple or malignant tumour of the cortex. Before puberty the phallus will be quite large, and there will be an absence of female sex characters 
and varying signs of precocious puberty and virilization. After puberty defeminization merging into virilization occurs and the clitoris rarely exceeds $1 \mathrm{~cm}$. in diameter.

Virilizing ovarian tumours-the arrhenoblastoma, hilar-cell tumour, or adrenal rest tumour-all secrete androgens of some kind, although the 17-ketosteroids may not always be elevated. The general picture is usually seen in adult life, and is one of defeminization and virilization (Foss and Leverton, 1959).

' Two other conditions deserve mention-constitutional virilism (Ferriman, Thomas, and Purdie, 1957), which is a common condition and may be familial or racial, and, finally, the Stein-Leventhal syndrome of hirsuties, obesity, amenorrhoea or oligomenorrhoea, and polycystic ovaries and infertility, which again probably occurs more often than is realized (Bailey, 1959).

The pseudofemale was a normal male in every respect before his conversion into an apparent female by means of massive and continued endocrine therapy and plastic surgery.

Similarly, the pseudomale is a hirsute well-muscled person who has been treated for years with androgens and usually had bilateral mastectomy and possibly plastic surgery to the external genitalia. It is not so easy for these patients to arrange for an oophorectomy or hysterectomy, and there is always the possibility that some gynaecological condition may arise. I know one such person who menstruates from time to time through her penile tube graft if she omits continuous androgen therapy.

, Now, as Cawadias (1959) has reminded us, sex is a matter of total personality, dependent on the psychological personality as well as the genes, gonads, genital organs, and endocrines. Thus the management of these cases may involve considerable care and responsibility.

In Canada, Moore (1959) has determined the nuclear sex in 3,700 newborn infants, about equally male and female anatomically. Five anatomical males showed the presence of female nuclear chromatin. By the use of this simple screening test as a routine, it would be possible then to investigate the true chromosomal sex of babies in a doubtful category, and this would facilitate their correct upbringing, and treatment if necessary.

\section{REFERENCES}

Arneaud. J. D., Annamunthodo, H., Pinkerton, J. H. M., and Cole, W. R. (1956). Brit. med. J., 2, 792

Bailey, K. V. (1959). J. Obstet. Gynaec. Brit. Emp., 66, 556

Barr. M. L. (1955). Anat. Rec., 121, 387.

Broster. L. R., Patterson, J., and Camber, B. (1953). Brit. med. J., 2. 1288 .

Cawadias, A. P. (1959). Lancet, 1, 369

Ferguson-Smith. M. A., Lennox, B., Mack, W. S., and Stewart, J. S. S. (1957). Ibid., 2, 167 .

Ferriman, D., Thomas, P. K., and Purdie, A. W. (1957). Brit. med. J., 2. 1410 .

Foss, G. L., and Leverton, J. S. (1959). J. Obstet. Gynaec. Brit. Emp., 66, 632.

Goldberg, M. B., and Maxwell, A. F. (1948). J. clin. Endocr., 8 , 367.

Grumbach, M. M., Blanc, W. A., and Engle, E. T. (1957). Ibid., 17, 703 .

Harnden, D. G., and Armstrong, C. N. (1959). Brit. med. J., 2, 1287. Hayles, A. B., and Nolan, R. B. (1958). Proc. Mayo Clin.. 33,

Heller, C. G., and Nelson, W. O. (1945). J. clin. Endocr., 5, 1. (1948). Ibid., 8, 345.

Hinman. F. (1935). Principles and Practice of Urology. Saunders, Philadelphia and London.

Jacobs, P. A., Baikie, A. G., Court Brown, W. M., Forrest, H., Roy, J. R., Stewart, J. S. S., and Lennox, B. (1959a). Lancet, 2. 591 .

D. MacGregor, T. N., Maclean, N., and Harnden, D. G. (1959b). Ibid., 2, 423 .
Jailer, J. W. (1953). Bull. N.Y. Acad. Med., 29, 377.

Jost, A. (1953). Recent Progr. Hormone Res., 8, 379

Klinefelter, H. F., jun., Reifenstein. E. C., jun., and Albright, F. (1942). J. clin. Endocr.. 2, 615

Moncrieff, A. (1958). Lancet, $2,267$.

Moore, K. L. (1959). Ibid., 1, 217.

Nellhaus, G. (1958). New Engl. J. Med., 258, 935.

Stern, C. (1959). Lancet, 2.1088.

Stewart, J. S. S. (1959a). Ibid.. 1, 1176.

(1959b). Proc. roy. Soc. Med., 52, 817

- Ferguson-Smith, M. A., Lennox, B., and Mack, W. S. (1958) Lancet, 2, 117 .

Wilkins, L. (1957). Diagnosis and Treatment of Endocrine Disorders in Childhood and Adolescence, 2nd ed. Blackwell, Oxford.

Jones, H. W., jun., Holman, G. H., and Stempfel, R. S., jun. (1958). J.' clin. Endocr., 18, 559 .

\section{TREATMENT OF RENAL FAILURE IN A UNIT WITH FACILITIES FOR HAEMODIALYSIS (TWIN-COIL ARTIFICIAL KIDNEY)}

\section{RESULTS WITH 80 PATIENTS}

R. C. JACKSON, F.R.C.P.Ed.

Group-Captain, Officer-in-Charge Medical Division and Renal Unit

N. V. D. BUNKER, M.B., B.Chir. Flight-Lieutenant

W. J. ELDER, M.B., B.S. Flight-Lieutenant

AND

A. M. JOEKES, M.A., M.R.C.P.

Civil Principal Specialist in Renal Disorders to the Royal Air Force; Senior Lecturer, Institute of Urology, London, and Honorary Physician to Associated Hospitals

From the Renal Unit, Princess Mary's Royal Air Force Hospital, Halton, Bucks

Owing to the many and varied causes of acute renal failure, clinicians in practically every branch of medicine and surgery are faced from time to time with the problems of treatment of this condition. Conservative management of acute renal failure in the last 10 years has greatly improved results. It is now clear that haemodialysis with an artificial kidney is an important adjunct to treatment.

Since June, 1957, we have employed an artificial kidney (Kolff twin coil) at this unit. We give a brief survey of the treatment of patients admitted to the unit during the first two years since haemodialysis was available. No previous results with this type of artificial kidney have been published in this country apart from a short summary (Jackson, 1958). During the two-year period 78 patients have been admitted and 88 dialyses performed on 57 of them. A further two patients were dialysed once each in their own hospitals. The patients, $75 \%$ of whom were civilians, have been referred from over a wide area, mainly from the Midlands, South of England, and Wales.

In any unit admitting patients primarily for the treatment of renal failure, a considerable number will be found eventually to be in the terminal phase of a chronic renal disease, or to have an acute irrecoverable renal lesion, such as bilateral cortical necrosis or a rapidly progressive glomerulonephritis. The results of treatment of patients with an acute recoverable lesion 